\title{
Colourimetric analysis of some powdered medicinal herbs from Ogbomoso, Nigeria
}

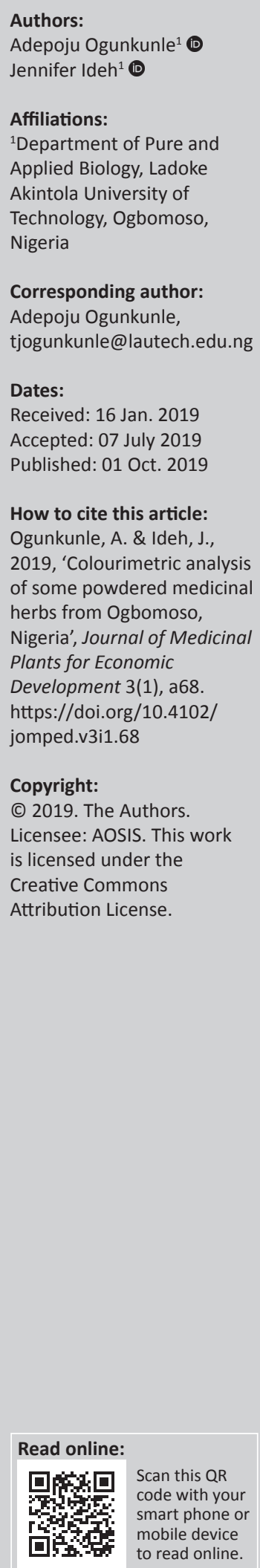

Background: The organoleptic evaluation of herbal drugs is as old as science, but the authentication of herbs on the basis of their fluorescence characteristics is difficult and sometimes impracticable because humans are limited by their sense of colour recognition.

Aim: This article undertakes a computer-aided examination of some powdered herbal materials with a view to characterising them calourimetrically, thus providing a reliable organoleptic clue for their authentication, against possible misidentification.

Setting: Research was conducted in Ogbomoso, Nigeria.

Methods: Seventeen herbal materials (i.e. stem bark, root/root bark, vines, fruit calyx, leaf sheath and seed) used for two traditional powdered drugs were collected and pulverised into powders. Their colours were digitised by scanning the surface of the powders in petri dishes using a CamScanner installed on a Samsung Galaxy Tablet 10.1 Model 7500, and were qualitatively and quantitatively analysed by uploading the images into the online Cool Hypertext Preprocessor (Cool PHP) software tool, setting the number of colours at five, thus giving consideration to only five dominant colour shades in each image, all expressed as hexadecimal codes. The codes were uploaded into Chir.ag/art, another online tool, to read off the colour names. The relative mean percentage, frequency and relative colour intensity (RCI) of each colour shade were calculated, and the colour with the highest RCI was taken as the first or typical colour of each herb.

Results: Nine of the 62 colours observed, namely Lucky, Sandrift, Cannon Pink, Potters Clay, Mandalay, Ferra, Domino, Russet and Roti, were highly restricted in distribution, each being the first or typical colour in only one species of the herbs (i.e. Enantia chlorantha, Garcinia kola, Hibiscus sabdariffa, Khaya senegalensis, Sarcocephalus latifolius, Sorghum bicolor, Theobroma cacao, Uvaria chamae and Zanthoxylum zanthoxyloides respectively). These colours were therefore substantially diagnostic of those herbs. Another nine colours among the most frequently observed colours and the number of species that had them were Pesto (9), Shadow (8), Driftwood (8), Barley Corn (5), Domino (4), Roman Coffee (4), Cape Palliser (4), Himalaya (4) and Husk (4); these were less diagnostic of the herbs in question. Based on the distribution of these colours, a diagnostic PHP colour chart was constructed for the authentication of the powdered medicinal herbs.

Conclusion: Powders of the 17 medicinal herbs analysed have been characterised colourimetrically with each species being unambiguously diagnosed. The study has therefore circumvented the subjectivity of the human sense of colour recognition in medicinal herb authentication.

Keywords: medicinal herb authentication; pharmacognosy; colourimetry; organoleptography; hexadecimal colour codes; herb misidentification; standardisation of herbal medicine.

\section{Introduction}

Medicinal plants are moving from fringe to main-stream use, with a greater number of people seeking herbal remedies for the improvement and sustenance of their health (Saha et al. 2010). However, according to Prasad et al. (2012), a key obstacle, which has hindered the acceptance of alternative medicine in certain parts of the world, is the lack of documentation and stringent quality control. There is therefore a necessity for increased efforts in the documentation of research work carried out on traditional medicine. Against this backdrop, it becomes extremely important to make an effort towards the standardisation of plant materials to be used as medicine. The goal of the standardisation of herbs is achievable through a number of techniques, with the basic ones being stepwise pharmacognostical and phytochemical studies (Prasad et al. 2012). These studies help in the authentication and standardisation of the plant materials. Correct identification and quality 
assurance of the starting materials is an essential prerequisite to ensuring the reproducible quality of herbal medicine, which will contribute to its safety and efficacy (Kunle, Egharevba \& Ahmadu 2012). Powdered herbal formulations have always been used as therapeutic agents for many health conditions in different parts of the world. However, African herbal products have been said to lack adequate scientific documentation, which could place them on a par with those from other parts of the world such as in India and China with regard to worldwide acceptability (Patwardhan et al. 2005).

Extensive use of herbal medicine calls for accurate and efficient means of authenticating herbs. This is necessary for two main reasons: firstly, the growing market for herbal medicine worldwide has endangered many international trading companies and generated an increase in counterfeit herbs and herbs of questionable quality. Secondly, herbal drugs are often taken as combinations that generate unique problems of authentication such as determining if there is species confusion of different herbs sharing one name or one herb using different names, and if correct herbal medicine has been included in a particular proprietary medicine (Gurav \& Gurav 2014). The adulteration of a herbal drug that often results from herb misidentification can cause serious health problems to the consumers, as well as publicity and legal headaches for the pharmaceutical industry. Many poisoning incidents caused by misuse or confusion of herbal medicine have raised international concern for the authentication of herbal medicines for their safe and effective use (Gurav \& Gurav 2014).

Malaria fever is a major public health problem in Nigeria (WHO 2013) and is responsible for over $70 \%$ of outpatient hospital visitations with a great toll on productivity (Oyibo et al. 2008; Obimakinde \& Simon-Oke 2017). Similarly, anaemia has been acknowledged as the most common pathological disorder, affecting a large section of the population of developing countries like Nigeria, with a varied prevalence, aetiology and degree of severity (Esike et al. 2016). For these reasons, this study focused on medicinal herbs for antimalarial and haematinic (blood enriching) herbal formulations in Ogbomoso, Nigeria.

The constant evolution of the malaria parasite has rendered the cheapest and most widely available antimalarial treatments ineffective, more so with the recent reports about the increasing resistance of Plasmodium falciparum to artemisininbased compounds (WHO 2018). Nowadays, antimalarial drug resistance has become one of the most important challenges to malaria control efforts (Al-Adhroey et al. 2010). If we should rely on herbal drugs as a saving grace in the management of this dreaded disease, then concerted efforts towards establishing an acceptable and authentic herbal raw material are a 'must do'. This was an area of focus in this study.

In a report of the World Health Organization, iron deficiency is stated as the most common type of anaemia estimated to affect approximately 2 billion people worldwide
(Wagstaff \& Claeson 2004). The treatment of anaemia depends on the confirmed diagnosis and severity of the disease. It includes iron therapy (oral and parenteral), iron polymaltose complex, folic acid and vitamin B12 supplementation, erythropoietin, bone marrow transplantation, et cetera.

The most prominent complication of iron therapy is gastrointestinal distress, with possible symptoms being abdominal pain, nausea, vomiting or constipation that often lead to non-compliance (Braunwald et al. 2001). Therefore, as an alternative, herbal drugs are being advocated by traditional healers for the treatment of anaemic conditions that they claim are effective with no side effects. Again, if the use of haematinic herbal formulations will enjoy any form of acceptability, its standardisation must be taken with much desired seriousness. The botanical constituents, mineral elements' composition and ascorbic acid contents of Maloff-HB (antimalarial) and Haematol-B (haematinic) traditional oral powdered drugs from Ogbomoso have been reported (Ogunkunle, Bello \& Ogundola 2014a; Ogunkunle et al. 2014b), but pharmacognostic evaluation of the constituent herbs is lacking. This study therefore examined the fluorescence properties of the powdered forms of the herbal materials with a view to characterising them colourimetrically, with the goal of providing a reliable organoleptic clue for their authentication, against possible misidentification.

The science of measuring colour and colour appearance is known as colourimetry (Gamma Scientific 2017), which is the application used to quantify the response of the human visual system and match human colour perception for applications in a variety of industries. It involves measuring the quality of a colour by comparison with standard colours or combinations of colours. In order to characterise a powdered herb by colour, the oldest practice for the researchers is to visually examine it and describe its colour as far as they can. This procedure has a limitation in that it can rarely detect whether the powder has an adulterant or is pure, without a bulking agent (Indigo Herbs 2019). In recent times, the practice has been to dissolve the powder in some suitable solvent, incubate the mixture for some time, decant the extract of the drug and visually compare the colour solution with known standard colour charts (Nanna et al. 2013; Nagulan \& Kumar 2016; Vankantesh et al. 2008). Even with such innovation, the subjective power of human vision is still a factor for concern.

Another technique for identifying the powder of herbal material in the pharmaceutical industry is manual microscopy. For this procedure, human expertise is required, and, in practice, a limited quantity of the sample is tested. Vyas et al. (2016) have however improved upon the procedure for identifying microscopic objects in powdered herbs by proposing an algorithm that automatically performs the task with a computer.

Colour is one of the most important characteristics in the sensory evaluation of herbs. According to Wang et al. (2012), 
sensory evaluation is an ancient method that remains important in the current quality control system of traditional medicine. The process is rapid and convenient when evaluating the quality of crude materials especially in a market. However, sensory evaluation has been met with scepticism because it is mainly based on experience and lacks a scientific basis. Recognising this weakness of the procedure, Wang et al. (2012) have demonstrated how colour-based sensory evaluation could differentiate the quality of herbal medicines objectively, and concluded that colour or colour parameters such as the values of the Red, Green, Blue (RGB) hues of light provided important information for the classification of the quality of some traditional Chinese medicines.

Going along the line of thought presented by Wang et al. (2012), herbal materials could be evaluated colourimetrically, even without the use of a colorimeter, a standard instrument for measuring the intensity of colour. Therefore, this study reiterated the importance of colour as an organoleptic parameter of medicinal herbs and its evaluation by means of a computer.

\section{Materials and methods Collection of plant materials}

All of the 17 herbal materials for the formulation of the Maloff-HB and Haematol-B powdered drugs as listed in Table 1 were collected from medicinal herb sellers in Ogbomoso land. The collected herbal materials were authenticated based on consultations with some experts in the Department of Pure and Applied Biology, Ladoke Akintola University of Technology, Ogbomoso. Where applicable, further authentication was performed by interacting with experienced traditional medicine practitioners from within and outside the town.

\section{Preparation of powdered samples}

Pulverisation (or milling) of the stem barks or root barks or roots was carried out using a modified form of the procedure, described by Ogunkunle et al. (2014a) as follows: the dried plant materials were chipped, cleaned first in water, followed by cleaning in absolute ethanol and then in distilled water, re-dried in an oven at $40{ }^{\circ} \mathrm{C}$ for $40 \mathrm{~min}$, dry-milled separately with a manual kitchen grinder and blended into fine powder in a kitchen blender with mill. Sieving of each fraction was carried out using a laboratory sieve with a $600-\mu \mathrm{m}$ pore size and then kept sealed in small plastic bags (at the laboratory temperature of $29^{\circ} \mathrm{C}-32^{\circ} \mathrm{C}$ ) ready for analysis. The interiors and exteriors of the grinder, blender and sieve were all surface-sterilised with absolute ethanol, just before each of the operations. Milling of the softer herbs such as the vines of Cassytha filiformis, seeds of Garcinia kola, fruit calyx of Hibiscus sabdariffa and leaf sheaths of Sorghum bicolor was carried out directly in the blender after oven drying.

\section{Colourimetric analysis of the powdered herbs}

A newly developed computer-aided organoleptic evaluation of colours of all the 17 medicinal herbs was carried out as described in the following sections.

\section{Homogenisation of herb powders}

A clean $8.5-\mathrm{cm}$ wide $\times 1.4-\mathrm{cm}$ deep disposable petri dish was filled to near the brim with the powder of each of the herbs and placed on a white paper background spread on a table outside the laboratory building. With the lid in place, the petri dish was held in-between the thumb and the index finger and gently shaken sideways for a moment to ensure that the powder was evenly distributed with a smooth surface consistency. The lid was removed and if flakes of the powder were observed on the surface, they were carefully

TABLE 1: A list of the plant parts used for two powdered herbal formulations (Maloff-HB and Haematol-B) in Ogbomoso for the colorimetric analysis.

\begin{tabular}{|c|c|c|c|c|c|c|}
\hline \multirow[t]{2}{*}{$S / N$} & \multirow[t]{2}{*}{ Species name } & \multirow[t]{2}{*}{ Family name } & \multirow[t]{2}{*}{ Local name } & \multicolumn{2}{|c|}{ Parts used in herbal formulations } & \multirow{2}{*}{$\begin{array}{l}\text { Parts analysed } \\
\text { colourimetrically }\end{array}$} \\
\hline & & & & $\begin{array}{l}\text { Antimalarial } \\
\text { (Maloff-HB) }\end{array}$ & $\begin{array}{l}\text { Haematinic } \\
\text { (Haematol-B) }\end{array}$ & \\
\hline 1 & Alstonia boonei De Wild & Apocynaceae & Ahun & Stem bark & - & Powdered stem bark \\
\hline 2 & Aristolochia ringens Vahl. & Aristolochiaceae & Akogun & - & Root & Powdered root \\
\hline 3 & Calliandra haematocephala Hassk. & Fabaceae & Tude & Root & - & Powdered root \\
\hline 4 & Cassytha filiformis L. & Lauraceae & Omonigelegele & Vines & - & Powdered vines \\
\hline 5 & Enantia chlorantha Oliv & Annonaceae & Dokitaigbo & Stem bark & - & Powdered stem bark \\
\hline 6 & Garcinia kola Heckel & Guttiferae & Orogbo & - & Seed & Powdered seed \\
\hline 7 & Hibiscus sabdariffa L. (red variety) & Malvaceae & Isapa pupa & - & Fruit calyx & Powdered fruit calyx \\
\hline 8 & Khaya senegalensis (Desr.) A. Juss & Meliaceae & Agano & - & Stem bark & Powdered stem bark \\
\hline 9 & Mangifera indica $\mathrm{L}$. & Anacardiaceae & Mangoro & Stem bark & Stem bark & Powdered stem bark \\
\hline 10 & Okoubaka aubreviilei Phelleg et Nomand & Santalaceae & Iginla & Stem bark & - & Powdered stem bark \\
\hline 11 & Parquetina nigrescens (Afz.) Bullock & Periplocaceae & Ogbo & Root bark & - & Powdered root \\
\hline 12 & Pterocarpus osun Craib. & Papilionaceae & Igiosun & Stem bark & - & Powdered stem bark \\
\hline 13 & Sarcocephalus latifolius (J.E. Smith) E.A. Bruce & Rubiaceae & Egbesi & Root bark & Root bark & Powdered root bark \\
\hline 14 & Sorghum bicolor Moench. & Poaceae & Oka baba & - & Leaf sheath & Powdered leaf sheath \\
\hline 15 & Theobroma cacao L. & Sterculiaceae & Cocoa & - & Stem bark & Powdered stem bark \\
\hline 16 & Uvaria chamae P. Beauv. & Annonaceae & Eruju & - & Root bark & Powdered stem bark \\
\hline 17 & Zanthoxylum zanthoxyloides & Rutaceae & Igiata & - & Root bark & Powdered root bark \\
\hline
\end{tabular}

Source: Adapted from Ogunkunle, A.T.J., Oyelakin, T.M., Enitan, A.O. \& Oyewole, F.E., 2014b, 'A quantitative documentation of the composition of two powdered herbal formulations (antimalarial and haematinic) using ethnomedicinal information from Ogbomoso, Nigeria', Evidence-Based Complementary and Alternative Medicine 2014, Article ID 751291, 8 pages. https://doi.org/ $10.1155 / 2014 / 751291$

-, not applicable. 
removed by means of a spatula and shaking followed with the lid on, until the powder was substantially free of flakes. Finally, the lid was removed for the colour of the powder to be digitised.

\section{Digitisation of colours of the samples}

The surface of the powder was scanned by means of a CamScanner (2013 IntSig Information Co., Limited) installed on a Samsung Galaxy Tablet 10.1 Model 7500. Scanning of each herb was performed in three replicates in June 2017 under natural outdoor lighting between 12:00 and 14:00 Nigerian time and at a close range of $8 \mathrm{~cm}-10 \mathrm{~cm}$. After the first scanning exercise, subsequent scans were obtained by firstly turning the powder in the petri dish with a spatula for a while to re-homogenise it, and shaking the petri dish gently to obtain an even surface consistency. The three digital images obtained were transferred into the memory of an HP laptop with an Intel Centrino processor, for further analysis.

\section{Qualitative and quantitative analyses of the colours}

To obtain some qualitative and quantitative information from the colours of the medicinal herbs, the replicated scanned images were uploaded, one at a time from the computer memory, into the Internet-based Cool Hypertext Preprocessor (Cool PHP) software tool (www.coolphptools. com/color_extract). The application software, which is equipped with an Hypertext Markup Language (HTML) embedded web scripting language, was run with 'number of colours' set at 5 and delta (i.e. distance in-between colour shades) at 10, thus giving consideration to only the first five dominant colour shades that made up the colour of each herb.

From the output of the colour analysis, the hexadecimal colour codes and the percent value of each of the five colour codes generated by the computer were noted. Following the assumption that only these five colours made up the colour of the scanned image, the five hexadecimal codes generated from the herb were entered, one at a time, into Chir.ag/art (www.chir.ag/projects/name-that-color/), the online application software, to read off the names of the colours that matched the supplied codes. Additionally, the relative percentage of each of the five colours for that replicate scan was computed and summed up to $100 \%$. The same process was repeated for the other two replicates of the herb image and the mean percentage for each colour was calculated from the three replicates.

In an attempt to objectively characterise the powdered herbs colourimetrically, the intensity of each colour was calculated by using the available information on energy quantification to derive a suitable formula. A clue from the formulae for calculating light and wave intensities as stated by Math Captain (2018) and Elert (2018), respectively, and expressed as power emitted or exerted by a source over a given surface area is as follows:
$I=P / A$

where $P$ is power in watts and $A$ is the surface area in square metre.

Colour intensity was operationally conceived, not in its strict sense (of purity) but as the strength of a colour in terms of its quantity or severity in a given medium. This conception relates to the manifestation of energy (such as light, sound, force, etc.) rather than to colourimetry in its strict sense. With this background, colour intensity or colour saturation was operationally defined in this study as a combination of its amount or quantity (in \%) and its frequency of occurrence on the surface area of the substance colourimetrically analysed. Hence, colour intensity defines the strength of that colour in the herb and was calculated as follows:

Colour intensity $(\%)=\frac{\begin{array}{c}\text { Relative mean } \\ \text { percentage of colour }\end{array}}{\begin{array}{c}\text { Total number of colours } \\ \text { generated from the samples }\end{array}} \times$ Frequency

where frequency $=$ the number of times in which the colour occurred throughout the entire sample.

Following the computation of the intensity of each colour, a sum of all the values for all the colours encountered in each herb was obtained and equated to 100, on the basis of which the relative colour intensity, that is the RCI of each colour, was calculated. The colour with the highest RCI was taken as typical or representative of the powdered herb analysed. The typical colour is that by whose name and hexadecimal code the herb can be precisely and objectively described.

\section{Ethical considerations}

This article followed all ethical standards for research without direct contact with human or animal subjects.

\section{Results and discussion}

The summaries of results of colourimetric evaluation of the herbs are shown in Tables 2 and 3. A total of 62 colours were encountered throughout the powdered samples of the 17 herbs. These colours differed widely with respect to their distribution and frequency of occurrence across the species (Table 2). The five most often encountered colours and their frequency values as indicated in Table 2 were Pesto (31), Shadow (21), Barley Corn (15), Driftwood (14) and Luxor Gold (11), while 19 of the colours were seldom encountered, having a frequency value of 1 . The colours with relatively wide distribution among the herbs were Driftwood and Barley Corn, found in eight and five species, respectively; and Cape Palliser, Domino and Husk, each of which was observed in four species. On the other hand, 44 of the colours were highly restricted in distribution, being found in only one or two species of the 17 medicinal herbs (Table 2).

The results in Table 3 attest to the fact that colourimetric information on the powdered herbs studied is diagnostic of 
TABLE 2: Distribution of all the colours observed in the powdered medicinal herbs analysed colourimetrically

\begin{tabular}{|c|c|c|c|c|}
\hline$S / N$ & Colour name & $\begin{array}{c}\text { Overall } \\
\text { frequency }\end{array}$ & $\begin{array}{l}\text { No. of herbs } \\
\text { found }\end{array}$ & Distribution (species names) \\
\hline 1 & Anzac & 1 & 1 & UVCH \\
\hline 2 & Au Chico & 2 & 1 & SOBI. \\
\hline 3 & Avocado & 2 & 1 & GAKO \\
\hline 4 & Barley Corn & 15 & 5 & ARRI; GAKO; OKAU; THCA; PANI \\
\hline 5 & Brown & 1 & 1 & SALA \\
\hline 6 & Camelot & 2 & 1 & HISA \\
\hline 7 & Cannon Pink & 3 & 1 & HISA \\
\hline 8 & Cape Palliser & 8 & 4 & KHSE; OKAU; PTOS; THCA \\
\hline 9 & Cod Grey & 1 & 1 & $S O B I$ \\
\hline 10 & Copper Rust & 5 & 2 & $H I S A ; S O B I$ \\
\hline 11 & Coral Tree & 3 & 1 & HISA \\
\hline 12 & Di Serria & 1 & 1 & UVCH \\
\hline 13 & Domino & 8 & 4 & CAHA; GAKO; GAKO; THCA \\
\hline 14 & Don Juan & 2 & 1 & $S O B I$ \\
\hline 15 & Driftwood & 14 & 8 & $\begin{array}{l}\text { ALBO; ARRI; CAFI; MAIN; PANI; } \\
\text { PTOS; THCA, ZAZA }\end{array}$ \\
\hline 16 & Eclipse & 1 & 1 & $S O B I$ \\
\hline 17 & Eggplant & 1 & 1 & $S O B I$ \\
\hline 18 & Espresso & 2 & 2 & KHSE; UVCH \\
\hline 19 & Ferra & 2 & 1 & $S O B I$ \\
\hline 20 & Gimblet & 3 & 2 & GAKO; PANI \\
\hline 21 & Go Ben & 2 & 2 & CAHA; PANI \\
\hline 22 & Golden Grass & 2 & 2 & ENAC; SALA. \\
\hline 23 & Hacienda & 4 & 2 & ENAC; SALA \\
\hline 24 & Hawaiian Tan & 6 & 3 & ENAC; SALA; UVCH \\
\hline 25 & Hillary & 2 & 1 & GAKO \\
\hline 26 & Himalaya & 5 & 4 & MAIN; SALA; UVCH; ZAZA \\
\hline 27 & Hippie Pink & 3 & 1 & HISA \\
\hline 28 & Hokey Pokey & 2 & 2 & ENAC; SALA \\
\hline 29 & Husk & 4 & 4 & ARRI; MAIN; OKAU; ZAZA \\
\hline 30 & Indian Khaki & 1 & 1 & PANI \\
\hline 31 & Lipstick & 1 & 1 & PTOS \\
\hline 32 & Lucky & 5 & 2 & ENAC; SALA \\
\hline 33 & Luxor Gold & 11 & 3 & $A L B O ; M A I N ; Z A Z A$ \\
\hline 34 & Mandalay & 4 & 2 & ENAC; SALA \\
\hline 35 & Metallic Bronz & 2 & 2 & KHSE; SOBI \\
\hline 36 & Muesli & 4 & 2 & OKAU; THCA \\
\hline 37 & Mule Fawn & 1 & 1 & KHSE \\
\hline 38 & Nero & 1 & 1 & $S O B I$ \\
\hline 39 & Old Copper & 3 & 1 & KHSE \\
\hline 40 & Old Gold & 1 & 1 & ENAC \\
\hline 41 & Old Rose & 1 & 1 & THCA \\
\hline 42 & Olive & 1 & 1 & ENAC \\
\hline 43 & Pesto & 31 & 9 & $\begin{array}{l}\text { ALBO; ARRI; CAFI; KHSE, MAIN; } \\
\text { OKAU; PTOS; PANI; UVCH }\end{array}$ \\
\hline 44 & Pizza & 3 & 2 & ENAC; SALA \\
\hline 45 & Porters Clay & 8 & 4 & KHSE; MAIN; PTOS; UVCH \\
\hline 46 & Quincy & 5 & 3 & CAHA; CAFI; OKAU \\
\hline 47 & Roman Coffee & 8 & 4 & CAHA; OKAU; PANI; THCA \\
\hline 48 & Roti & 4 & 3 & $A L B O ; U V C H ; Z A Z A$ \\
\hline 49 & Russet & 4 & 3 & KHSE; MAIN; UVCH \\
\hline 50 & Saffron & 1 & 1 & ENAC \\
\hline 51 & Sahara & 1 & 1 & ENAC \\
\hline 52 & Sandrift & 5 & 2 & GAKO; THCA \\
\hline 53 & Shadow & 21 & 8 & $\begin{array}{l}\text { ALBO; ARRI; CAHA; CAFI; OKAU; } \\
\text { PANI; PTOS; THCA }\end{array}$ \\
\hline 54 & Spicy Mix & 5 & 4 & CAHA; KHSE; OKAU; SOBI \\
\hline 55 & Straw & 1 & 1 & PANI \\
\hline 56 & Sycamore & 2 & 1 & $A R R I$ \\
\hline 57 & Tacha & 3 & 2 & $U V C H ; Z A Z A$ \\
\hline 58 & Tapestry & 1 & 1 & HISA \\
\hline 59 & Tussock & 3 & 3 & ALBO; MAIN; UVCH \\
\hline 60 & Twine & 1 & 1 & THCA \\
\hline
\end{tabular}

Table 2 continues on the next column $\rightarrow$
TABLE 2 (Continues...): Distribution of all the colours observed in the powdered medicinal herbs analysed colourimetrically $\dagger$.

\begin{tabular}{llccl}
\hline S/N & Colour name & $\begin{array}{c}\text { Overall } \\
\text { frequency }\end{array}$ & $\begin{array}{c}\text { No. of herbs } \\
\text { found }\end{array}$ & Distribution (species names) \\
\hline 61 & West Coast & 4 & 3 & CAFI; UVCH; ZAZA \\
62 & Woody Brown & 1 & 1 & SOBI \\
\hline
\end{tabular}

ALBO, Alstonia boonei (Stem bark); ARRI, Aristolochia ringens (Root); CAHA, Calliandra haematocephala (Root); CAFI, Cassytha filiformis (Vines); ENAC, Enantia chlorantha (Stem haematocephala (Root); CAFI, Cassytha filiformis (Vines); ENAC, Enantia chlorantha (Stem bark); GAKO, Garcinia kola (Seed); HISA, Hibiscus sabdariffa (Fruit calyx); KHSE, Khaya senegalensis (Stem bark); MAIN, Mangifera indica (Stem bark); OKAU, Okoubaka aubreviile (Stem bark); PANI, Parquetina nigrescens (Root bark); PTOS, Pterocarpus osun (Stem bark) SALA, Sarcocephalus latifolius (Root bark); SOBI, Sorghum bicolor (Leaf sheath); THCA Theobroma cacao (Stem bark); UVCH, Uvaria chamae (Root bark); ZAZA, Zanthoxylum zanthoxyloides (Root bark); $\mathrm{S} / \mathrm{N}$, serial numbe

$\dagger$, Colour names according to www.chir.ag/projects/name-that-color/.

the species. Out of the 62 colours encountered across the 17 powdered herbs, $34(54.8 \%)$ are represented in the table. A cursory look at this table will show that only nine (approximately 53\%) of the 17 herbs (namely Enantia chlorantha, G. kola, H. sabdariffa, Khaya senegalensis, Sarcocephalus latifolius, S. bicolor, Theobroma cacao, Uvaria chamae and Zanthoxylum zanthoxyloides) can be clearly distinguished on the basis of their colours. This assertion comes from the information that the powders of only these nine species stand out by not sharing their typical colours with any other species, these are: Lucky, Sandrift, Cannon Pink, Potters Clay, Mandalay, Ferra, Domino, Russet and Roti, respectively (Table 3).

On the other hand, a more holistic observation into the results in Tables 2 and 3 reveals that the observed colours have resolved all the 17 (or 100\%) herbs into their constituent species. In the first place, Table 2 singles out 11 of the species studied as distinct entities from the evidence that certain colours are restricted to each of them, that is Aristolochia ringens (Sycamore), E. chlorantha (Old Gold, Olive, Saffron and Sahara), G. kola (Avocado and Hillary), H. sabdariffa (Camelot, Cannon Pink, Coral Tree, Hippie Pink and Tapestry), K. senegalensis (Mule Fawn and Old Copper), Parquetina nigrescens (Indian Khaki and Straw), Pterocarpus osun (Lipstick), S. latifolius (Brown), S. bicolor (Au Chico, Cod Grey, Don Juan, Eclipse, Eggplant, Ferra and Woody Brown), T. cacao (Old Rose and Twine) and $U$. chamae (Anzac and Di Serria). As such, in analysing any sample of these powdered herbs using the procedure adopted in this study, the so-called restricted colours can be used to precisely identify certain plant species. In the second place, the mutually exclusive typical colours of nine of the herbs in Table 3 are diagnostic of those species.

In Table 3, four species, that is, Alstonia boonei, C. filiformis, Mangifera indica and $P$. osun, all have Pesto as their typical colours. In a similar manner, A. ringens, Calliandra haematocephala, Okoubaka aubreviilei and P. nigrescens have Shadow as their respective typical colour. The fact that each of these two groups of herbs mentioned shares the same typical colour does not foreclose the use of other colours to diagnose them. By the time the second, third or fourth colour in the series is taken into consideration, all of the eight species would have been clearly identified (Table 3 ).

Organoleptic evaluation of herbal drugs is as old as science. In this practice, various sensory parameters of the plant material, such as colour, odour and taste, are evaluated and 


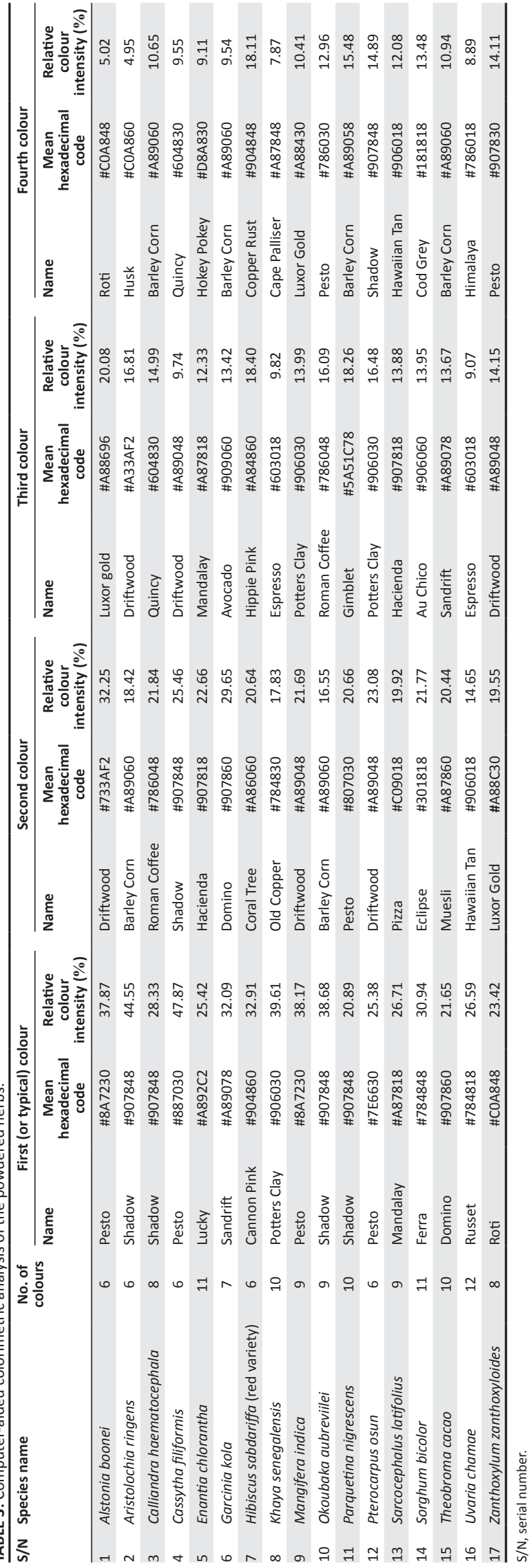

used to diagnose herbs (Ali 2009). It is argued that such a procedure is subjective because it is based on the whims and caprices of the observer. Authentication of medicinal herbs on the basis of their fluorescence characteristics is even more difficult and often found impracticable because humans are limited by their sense of colour recognition.

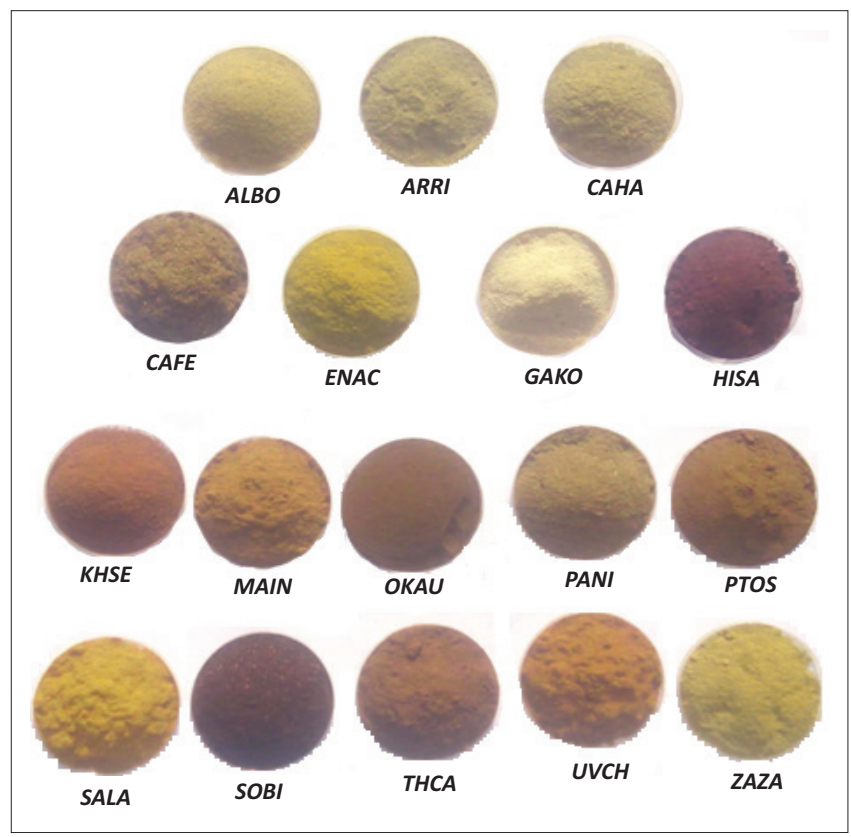

ALBO, Alstonia boonei (Stem bark); ARRI, Aristolochia ringens (Root); CAHA, Calliandra haematocephala (Root); CAFI, Cassytha filiformis (Vines); ENAC, Enantia chlorantha (Stem bark); GAKO, Garcinia kola (Seed); HISA, Hibiscus sabdariffa (Fruit calyx); KHSE, Khaya senegalensis (Stem bark): MAIN, Mangifera indica (Stem bark); OKAU, Okoubaka aubreviile (Stem bark). PANI, Parquetina nigrescens (Root bark); PTOS, Pterocarpus osun (Stem bark) SALA, Sarcocephalus latifolius (Root bark); $S O B I$, Sorghum bicolor (Leaf sheath). $T H C A$ Theobroma cacao (Stem bark); UVCH, UVaria chamae (Root bark); ZAZA, Zanthoxylum Theobroma cacao (Stem bark); UVCH, Uvaria chamae (Root bark); ZAZA, Zanthoxylum
zanthoxyloides (Root bark). FIGURE 1: Images of the powdered medicinal herbs prepared for colourimetric analysis

TABLE 4: Procedure for computer-aided colorimetric evaluation of herbal material.

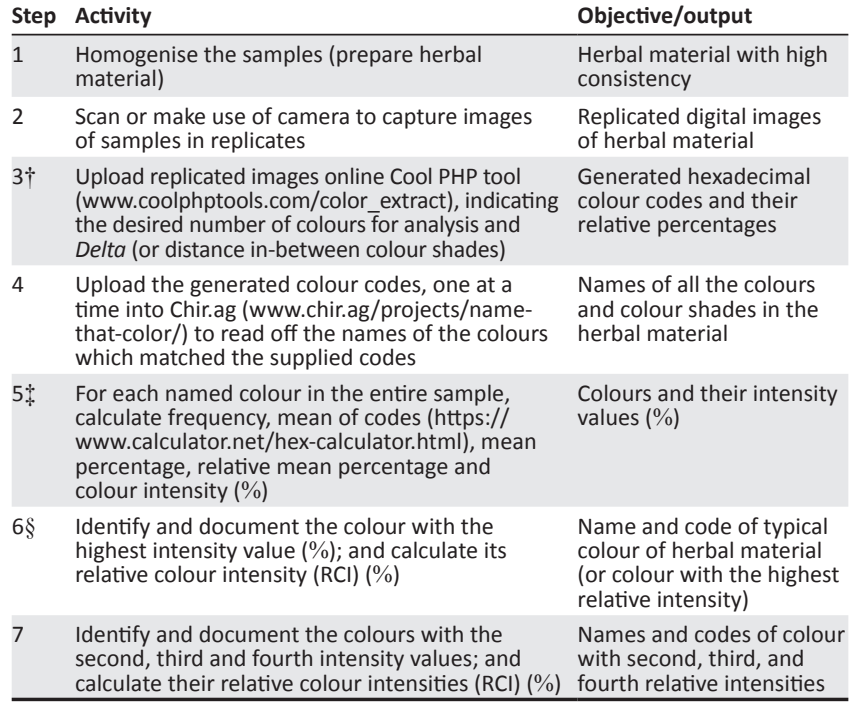
PHP, Hypertext Preprocessor.

$\dagger$, Recommended number of colours and Delta $D$ for powdered herbs are 5 and 10, respectively.

$\ddagger$, Colour intensity $(\%)=$ (relative mean percentage $\div$ total number of colours generated for herb) $x$ frequency (i.e. the number of times in which the colour occurred throughout the entire sample).

$\S$, Typical colour that is the final output of the algorithm is the colour with the highest intensity, and by which the herbal material can both be qualitatively (name) and quantitatively (hexadecimal code) characterised. 
The present study has succeeded to establish the colourimetric diagnostic features of powders of 17 of the medicinal herbs commonly used in Ogbomoso, Nigeria, the results of which can be employed as suitable quality control measures to ensure the quality, safety and efficacy of these drugs. Distinguishing these colours (Figure 1) with precision is not practicable with the human sense of vision, a challenge that has been adequately addressed through this study. Available information in the literature strongly suggests that this study could be the first attempt to characterise the colours of Nigerian herbal materials quantitatively. Hence, the computer-aided analysis of colour composition of herbs being reported is an enhancement of the science of pharmacognosy, having successfully circumvented the subjectivity of human senses. The results obtained from this study are not only diagnostic of the herbs colourimetrically, the unique procedure followed is also proposed as a protocol or template for the colourimetric evaluation of medicinal herbs (Table 4) and other plant materials.

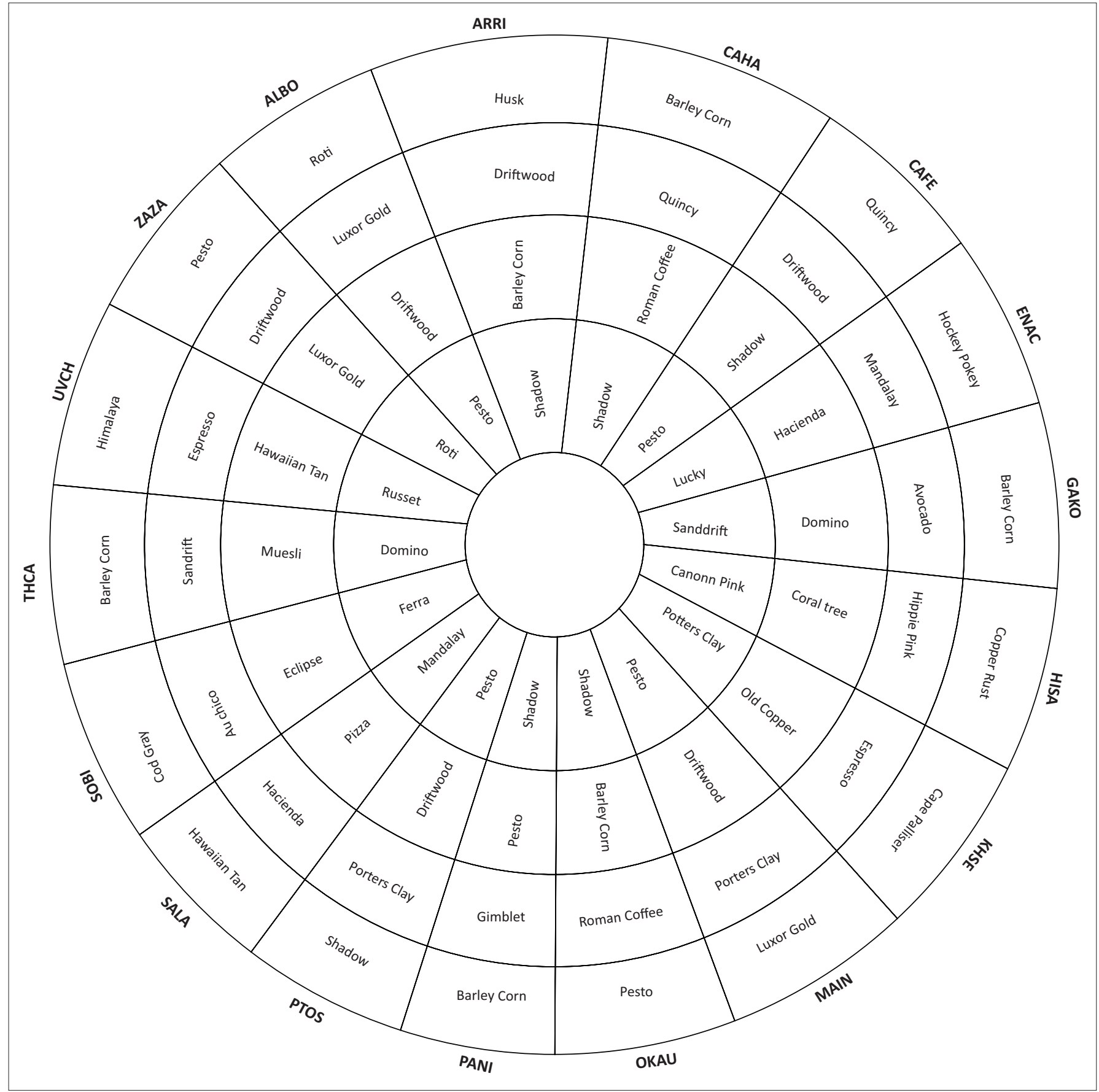

ALBO, Alstonia boonei; ARRI, Aristolochia ringens; CAHA, Calliandra haematocephala; CAFI, Cassytha filiformis; ENAC, Enantia chlorantha; GAKO, Garcinia kola; HISA, Hibiscus sabdariffa; KHSE, Khaya senegalensis; MAIN, Mangifera indica; OKAU, Okoubaka aubreviilei; PANI, Parquetina nigrescens; PTOS, Pterocarpus osun; SALA, Sarcocephalus latifolius; SOBI, Sorghum bicolor; THCA, Theobroma cacao; UVCH, Uvaria chamae; ZAZA, Zanthoxylum zanthoxyloides.

FIGURE 2: Diagnostic Hypertext Preprocessor colour chart for the powdered herbs studied. Colours in the innermost ring of boxes represent the typical colours (i.e. of the highest relative intensity value); those in the second ring represent the colours with the second highest intensity value; those in the third ring represent the colours with the third highest intensity value, while those in the outermost ring represent the colours with the fourth highest intensity value. 
The proposed protocol for colourimetric evaluation of herbal material can be seen to have succeeded in an attempt to characterise and diagnose the powdered herbs in this study as evidenced by the artificial key in Figure 2. In order to apply this key to diagnose any of the medicinal herbs indicated therein, the user should simply follow the recommended procedure laid out in Table 4, enter the key at the centre and proceed towards the circumference by selecting the colour names observable in the target powdered sample at the successive rings of boxes, thereby narrowing down on the choice of the possible identities of the herb until only one choice is achieved, which represents its identity.

\section{Conclusion}

Powders of the 17 herbs used in the formulation of two traditional oral powdered drugs in Ogbomoso were colourimetrically characterised quantitatively and qualitatively, with each species being unambiguously diagnosed. This study has therefore circumvented the subjectivity of the human sense of colour recognition in medicinal herb authentication. A circular diagnostic chart has also been presented as a possible taxonomic key format. Apart from adding novel information to the body of literature in systematic botany, the PHP colour chart is a useful tool for authenticating the medicinal herbs studied.

\section{Acknowledgements}

The authors thank Mr. Michael Ogunwole of the Postgraduate Laboratory, Department of Pure and Applied Biology, Ladoke Akintola University of Technology (LAUTECH), Ogbomoso, for technical assistance during the preparation of medicinal herbs for analysis.

\section{Competing interests}

The authors declare that they have no competing interests.

\section{Authors' contributions}

A.O. carried out the conceptualisation of the research, data analysis and manuscript preparation. J.I. did data collection, laboratory analyses and prepared the draft of the manuscript.

\section{Funding information}

This research received no specific grant from any funding agency in the public, commercial, or not-for-profit sectors.

\section{Data availability statement}

Data sharing is not applicable to this article as no new data were created or analysed in this study.

\section{Disclaimer}

The views and opinions expressed in this article are those of the authors and do not necessarily reflect the official policy or position of any affiliated agency of the authors.

\section{References}

Ali, M., 2009, Phamacognosy and phytochemistry, pp. 181-182, CBS Publishers \& Distributors, Delhi.

Al-Adhroey, A.H., Nor, Z.M., Al-Mekhlafi, H.M. \& Mahmud, R., 2010, 'Opportunities and obstacles to the elimination of malaria from Pennisula Malaysia: Knowledge, attitudes and practices on malaria among aboriginal and rural communities', Malaria Journal 9(1), 137. https://doi.org/10.1186/1475-2875-9-137

Braunwald, E., Fauci, A.S., Kasper, D.L., Hauser, S.L., Longo, D.L. \& Jameson, J.L., 2001, Harrison's principle of internal medicine, 15th edn., pp. 586-626, McGraw-Hill, New York.

Elert, G., 2018, Intensity: The physics hypertextbook, 1998-2018, Physics.info online Publishers, viewed 08 December 2018, from https://physics.info/intensity.

Esike, C.O., Anozie, O.B., Onoh, R.C., Sunday, U.C., Nwokpor, O.S. \& Umeora, O.U., 2016, 'The prevalence of anaemia in pregnancy at booking in Abakaliki, Nigeria', Tropical Journal of Obstetrics and Gynaecology 33(3), 332-336. https://doi.org/ 10.4103/0189-5117.199818

Gamma Scientific, 2017, What is colorimetry, viewed 06 December 2018, from www. gamma-sci.com/colorimetry/.

Gurav, S.S. \& Gurav, N.S., 2014, Indian herbal drug microscopy, Springer Science + Business Media, New York.

Indigo Herbs, 2019, How to take a herbal powder, IndigoHerbs, Meristem House, Wells Road, Glastonbury, England, viewed 05 January 2019, from www.indigoherbs.co.uk.

Kunle, F., Egharevba, O.H. \& Ahmadu, O.P., 2012, 'Standardization of herbal medicines: A review', International Journal of Biodiversity and Conservation 4(3), 101-112. https://doi.org/10.5897/IJBC11.163

Math Captain, 2018, Light intensity, viewed 08 December 2018, from https://formula. mathcptain.com/physics/intensity-of-light-formul.html.

Nagulan, S. \& Kumar, S.R., 2016, 'Phytochemical, physicochemical, and fluorescence analysis of leaf extracts of ZyzygiumcalophyllifoliumWalp', Asian Journal of Pharmaceutical and Clinical Research 9(1), 275-278.

Nanna, R.S., Banala, M., Palmulaparthi, A., Kurra, A. \& Kagithoju, S., 2013, 'Evaluation of phytochemicals and fluorescent analysis of seed and leaf extracts of Cajanuscajan L.', International Journal of Pharmaceutical Sciences Review and Research 22(1), 11-18, viewed from www.globalresearchonline.net.

Obimakinde, E.T. \& Simon-Oke, I.A., 2017, 'The prevalence of malaria infection among patients attending the Health Centre of the Federal University of Technology, Akure, Nigeria', International Journal of Tropical Disease \& Health 27(4), 1-7. https://doi.org/10.9734/IJTDH/2017/35340

Ogunkunle, A.T.J., Bello, O.S. \& Ogundola, A.F., 2014a, 'Ascorbic acid a mineral elements composition of powdered antimalarial (Maloff-HB) and heamatinic (Haematol-B) herbal formulations from Ogbomoso, Nigeria', African Journal of Biotechnology 13(24), 2466-2473. https://doi.org/10.5897/AJB2014.13808

Ogunkunle, A.T.J., Oyelakin, T.M., Enitan, A.O. \& Oyewole, F.E., 2014b, 'A quantitative documentation of the composition of two powdered herbal formulations (antimalarial and haematinic) using ethnomedicinal information from Ogbomoso, Nigeria', Evidence-Based Complementary and Alternative Medicine 2014, Article ID 751291, 8 pages. https://doi.org/10.1155/2014/751291

Oyibo, W., Fagbenro-Beyioku, A.F. \& Igbasi, U., 2008, 'Uses of medicinal plants in the treatment of malaria and gastrointestinal parasitic infections', in Odugbemi T. (ed.), A textbook of medicinal plants from Nigeria, pp. 243-256, University of Lagos Press, Akoka-Yaba, Lagos.

Patwardhan, B., Warude, D., Pushpangadan, P. \& Bhatt, N., 2005, 'Ayurveda and traditional Chinese medicine: A comparative overview', Evidence-Based Complementary and Alternative Medicine 2(4), 465-473. https://doi.org/10.1093/ ecam/neh140

Prasad, V., Rameshi, S.D., Rakesh, S.S., Karita, N.Y. \& Manohar, J.P., 2012, 'Pharmacognostic, phytochemical and physicochemical studies of Mimmusopselengi Linn stem bark (Sapotaceae)', Der Pharmacia Lettre 4(2), 607-613, viewed 20 August 2018, from www.scholarsresearchlibrary.com.

Saha, D., Pahari, S.K., Maity, T. \& Sur, D., 2010, 'Pharmacognostic studies of the bark of Parkinsonia aculeate', International Journal of Pharma Sciences and Research 1(11), 473-475.

Vankantesh, S., Reddy, Y.R.S., Rawesh, M., Swamy, M.M., Mahalevan, N. \& Swresh, B., 2008, 'Pharmacognostical studies on Dodonaea viscose', African Journal of Pharmacy and Pharmacology 2(4), 83-88.

Vyas, S., Fatamiya, B., Zaveri, T. \& Achaya, S., 2016, 'Identification and classification of powder microscopic images of Indian herbal plants', International Journal of Electronics and Communication Engineering \& Technology 7(3), 18-28. https:// www.iaeme.com/IJECET/issues.asp?JType.IJECET\&VType=7\&1Type=3.

Wagstaff, A. \& Claeson, M., 2004, The millennium development goals for health- rising to the challenges, World Bank, Washington, DC.

Wang, J.B., Zeng, L.N., Zang, Q.C., Gong, Q.F., Li, B.C., Zhang, X.R. et al., 2012, 'Colorimetric grading scale can promote the standardization of experiential and sensory evaluation in quality control of traditional Chinese medicines', PLoS One 7(11), e48887. https://doi.org/10.1371/journal.pone.0048887

World Health Organization (WHO), 2013, Malaria fact sheets, World Health Organization, Geneva, viewed 10 September 2018, from, https://www.who.int/ mediacentre/factsheets/fs094/en/.

World Health Organization (WHO), 2018, 'Malaria: Q \& A on artemisinin resistance', Strategy for malaria elimination in the Greater Mekong Subregion (2015-2030), viewed 08 December 2018, from www.who.int/malaria/media/artemisinin_ resistance_qa/en/. 